\title{
Glutathione $S$-Aralkyltransferase
}

\author{
By E. BOYLAND AND L. F. CHASSEAUD* \\ Chester Beatty Research Institute, Institute of Cancer Research : \\ Royal Cancer Hospital, London S.W. 3
}

(Received 9 July 1969)

\begin{abstract}
1. The name 'glutathione $S$-aralkyltransferase' is proposed for the enzyme catalysing the reaction of benzyl chloride with GSH. 2. Results from heat-inactivation studies, ammonium sulphate-fractionation and acid-precipitation experiments, and studies of the distribution of activities in rat liver, in rat kidney and in the livers of other animals indicate that glutathione $S$-aralkyltransferase differs from glutathione $S$-alkyltransferase, $S$-aryltransferase, $S$-epoxidetransferase and an $S$-alkenetransferase. 3. The distribution of these enzymes in the livers of the animal species examined was different. 4. Glutathione $\boldsymbol{S}$-alkyltransferase, $\boldsymbol{S}$-aralkyltransferase and the $S$-alkenetransferase that are present in rat liver supernatant were inhibited by GSSG, and the nature of the inhibition varied in each case. 5. 3,5Di-tert.-butyl-4-hydroxybenzyl acetate reacts spontaneously with GSH, but the rat liver-supernatant-catalysed reaction of GSH with this and other aralkyl esters was weak. 6. A probable function of the glutathione $S$-transferases is the protection of cellular constituents from strong electrophilic agents.
\end{abstract}

Glutathione $S$-transferases catalyse the reaction of GSH with a variety of foreign compounds (Booth, Boyland \& Sims, 1961; Al-Kassab, Boyland \& Williams, 1963; Boyland \& Williams, 1965; Johnson, 1966; Boyland \& Chasseaud, 1967; Chasseaud, 1967). This reaction appears to be an initial stage in mercapturic acid biosynthesis from these compounds (Barnes, James \& Wood, 1959; Boyland \& Chasseaud, 1969).

It was thought that glutathione $S$-aryltransferase, which catalyses the reaction of GSH with 1,2dichloro-4-nitrobenzene (Grover \& Sims, 1964), also catalyses the reaction of GSH with benzyl chloride (see Parke, 1968). However, Booth et al. (1961) showed that benzyl chloride is a noncompetitive inhibitor of glutathione $S$-aryltransferase, and Suga, Ohata, Kumaoka \& Akagi (1967) found that the ratio of activities in rat liver and in rat kidney for the enzyme catalysing the reaction of GSH with benzyl chloride was 100:73 compared with 100:8 for glutathione $S$-aryltransferase. These results suggest that the enzyme catalysing the reaction of GSH with benzyl chloride is not glutathione $S$-aryltransferase; this enzyme may be named glutathione $S$-aralkyltransferase, since benzyl chloride is an aralkyl halide.

This paper describes experiments showing that glutathione $\boldsymbol{S}$-aralkyltransferase differs from four other glutathione $S$-transferases that have been described (see Table 1).

* Present address: Huntingdon Research Centre, Huntingdon.

\section{EXPERIMENTAL}

Materials. Anthr-9-ylmethyl acetate, 3,5-di-tert.-butyl-4hydroxybenzyl acetate and 1-menaphthyl acetate (naphth1-ylmethyl acetate) were gifts from Dr P. Sims of this Institute; benzyl formate was a gift from Mr G. R. A. Short of Bush, Boake and Allen Ltd. (London E.8); p-nitrobenzyl acetate was from K \& K Laboratories Inc. (Plainview, N.Y., U.S.A.); methyl iodide was from May and Baker Ltd. (Dagenham, Essex); GSH was from Schwarz BioResearch Inc. (Mount Vernon, N.Y., U.S.A.); GSSG was from Sigma Chemical Co. (St Louis, Mo., U.S.A.); 1,2-dichloro-4nitrobenzene was a commercial sample recrystallized from ethanol; the remaining chemicals were from British Drug Houses Ltd. (Poole, Dorset).

Buffers. Pyrophosphate buffers were prepared from $\mathrm{K}_{4} \mathrm{P}_{2} \mathrm{O}_{7}$ and $\mathrm{Na}_{2} \mathrm{H}_{2} \mathrm{P}_{2} \mathrm{O}_{7}$ and orthophosphate buffers from $\mathrm{KH}_{2} \mathrm{PO}_{4}$ and $\mathrm{Na}_{2} \mathrm{HPO}_{4}$.

Thiol determination. In all experiments, GSH was determined by titration with iodate in the presence of iodide in sulphosalicylic acid; sodium starch glycollate was used as an indicator (Woodward \& Fry, 1932).

Tissue supernatants. Rat livers or rat kidneys were homogenized in 5 vol. of $0 \cdot 1 \mathrm{~m}$-orthophosphate buffer, pH 7.4, in a Potter-Elvehjem (1936) type homogenizer with a Teflon pestle. The homogenate was centrifuged at approx. $2000 \mathrm{~g}$ for $30 \mathrm{~min}$. and the turbid supernatant was centrifuged at $120000 \mathrm{~g}_{\mathrm{av}}$. for $80 \mathrm{~min}$. in an MSE Superspeed 65 centrifuge (Measuring and Scientific Equipment Ltd., London S.W.1.) with rotor no. 59594. The resulting clear supernatant (described as undialysed rat liver supernatant in Tables 2 and 3) was dialysed in Visking tubing against glass-distilled water at $\mathrm{pH} 7 \cdot 0$ and the small precipitate that separated was removed by centrifugation. This super. natant was used for all experiments unless otherwise stated. 
The $70000 g_{\text {av. supernatants were prepared as described }}$ above except that an MSE Highspeed 25 centrifuge was used, and the resulting supernatant was slightly turbid. All operations were carried out below $10^{\circ}$.

Dialysed liver supernatants from adult animals of differcnt species either were prepared as described above or had been prepared approx. 1-2 years earlier, as described by Boyland \& Chasseaud (1967), and stored at $-30^{\circ}$.

Rat liver supernatant fractionation. Adjustment of the $\mathrm{pH}$ of rat liver supernatant to $\mathrm{pH} \mathrm{5.0}$ and adsorptions on calcium phosphate gel were carried out as described by Boyland \& Chasseaud (1967), and acetone drying, heatinactivation and ammonium sulphate fractionation followed by acetic acid precipitation as described by Boyland \& Chasseaud (1968a).

Enzyme activity. Conjugations of GSH with benzyl chloride (3mM) and with all substrates were assayed as described by Boyland \& Chasseaud (1967), except that glutathione $S$-aryltransferase activity was assayed by the method of Grover \& Sims (1964) as modified by Boyland \& Chasseaud (1967). The amount of enzyme added was such that not more than $20 \%$ of the substrate reacted during the incubation. All determinations were corrected for any nonenzymic reaction. In any related set of experiments substrates were always assayed with the same specimen of treated supernatant at $\mathrm{pH} 6.5$ and $25^{\circ}$.

\section{RESULTS}

Methods previously used to separate glutathione $S$-transferases (Boyland \& Chasseaud, 1967, 1968a) were used to distinguish glutathione $S$-aralkyltransferase from glutathione $S$-alkyltransferase and $S$-aryltransferase, which are enzymes whose second substrates resemble benzyl chloride by also possessing a halogen atom and either an aromatic ring or an alkyl group or both (Table 1).

Glutathione $S$-aralkyltransferase was also compared with glutathione $S$-alkene (cis-ester)transferase and $S$-epoxidetransferase, but because of the type of second substrate catalysed these two enzymes are unlikely to be concerned with benzyl chloride (Table 1).

Heat inactivation. Heating of dialysed rat liver supernatant for $50 \mathrm{~min}$. at $\mathrm{pH} 7.4$ and $45^{\circ}$ decreased to differing extents the activities of glutathione $S$. alkyltransferase, $S$-aralkyltransferase and $S$-aryl- transferase, thereby differentiating between them (Fig. 1). Boyland \& Chasseaud (1968a) showed that, under these conditions, glutathione $S$-aryltransferase and $S$-epoxidetransferase were similar, as were glutathione $S$-alkyltransferase and $S$-alkene(cisester)transferase.

Fractionation of rat liver preparations. Results in Table 2 show that glutathione $S$-alkyltransferase and $S$-epoxidetransferase were less stable to the lowering of the $\mathrm{pH}$ of rat liver supernatant to $\mathrm{pH} \mathrm{5.0} \mathrm{than}$ were the remaining enzymes. These results were in agreement with those of Boyland \& Williams (1965), but Wit \& Snel (1968) showed that the activity of glutathione $S$-epoxidetransferase in a wild-bird liver $70000 \mathrm{~g}$ supernatant was unaffected.

Dialysis of rat liver supernatant showed no major differences between the enzymes, in contrast with the results of Boyland \& Williams (1965) and Johnson (1966), who found that glutathione $S$ alkyltransferase was almost inactivated. The differences between these results (Table 2) and those of Boyland \& Williams (1965) and Johnson (1966) are difficult to explain but were not due to the use of rat

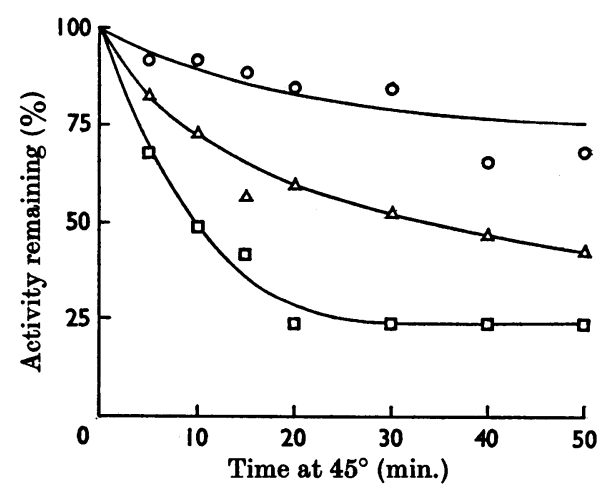

Fig. 1. Decrease in the activities of glutathione $S$-alkyltransferase $(\square), S$-aralkyltransferase $(\Delta)$ and $S$-aryltransferase $(O)$ after heating dialysed rat liver supernatant for $0-50 \mathrm{~min}$. at $\mathrm{pH} 7 \cdot 4$ and $45^{\circ}$. The activities of these enzymes were measured as described in the text.

Table 1. Some known glutathione S-transferases

Enzyme

GSH S-alkyltransferase

GSH $S$-aralkyltransferase

GSH S-aryltransferase

GSH $\boldsymbol{S}$-epoxidetransferase

GSH S-alkene(cis-ester)transferase

\author{
Second substrate catalysed \\ Methyl iodide \\ Benzyl chloride
}

1,2-Dichloro-4-nitrobenzene

2,3-Epoxypropylphenyl ether Diethyl maleate
Reaction products
$\mathrm{CH}_{3} \cdot \mathrm{SG}+\mathrm{H}^{+}+\mathrm{I}^{-}$
$\mathrm{Ph} \cdot \mathrm{CH}_{2} \cdot \mathrm{SG}+\mathrm{H}^{+}+\mathrm{Cl}^{-}$

$\mathrm{C}_{2} \mathrm{H}_{5} \cdot \mathrm{O}_{2} \mathrm{C} \cdot \mathrm{CH}(\mathrm{SG}) \cdot \mathrm{CH}_{2} \cdot \mathrm{CO}_{2} \cdot \mathrm{C}_{2} \mathrm{H}_{5}$

* The orientation of the GSH residue is uncertain. 


\section{Table 2. Separation of glutathione S-transferases}

Rat liver preparations and measurements of enzyme activity are described in the text. Non-enzymic reaction was less than $2 \%$ in all cases. All assays were at $\mathrm{pH} 6.5$ and $25^{\circ}$ for $5 \mathrm{~min}$. The numbers in parentheses are the numbers of separate experiments from which these results were averaged. For each experiment, the activity of the corresponding undialysed rat liver supernatant was also assayed and the activity observed for other preparations was expressed as a percentage of this. Activities were calculated as $\mu$ moles of thiol lost/min./g. of tissue.

Rat liver preparations

Undialysed rat liver supernatant (control activity)

Dialysed rat liver supernatant (3)

Supernatant obtained after lowering $\mathrm{pH}$ to $5 \cdot 0$ and then raising $\mathrm{pH}$ to $6.5(2)$

Supernatant obtained after lowering $\mathrm{pH}$ to $\mathbf{5 \cdot 0}$ and acetone drying (2)
$\%$ of activity remaining towards

\begin{tabular}{rcccc}
\hline alkyl & aralkyl & aryl & alkene & epoxide \\
100 & 100 & 100 & 100 & 100 \\
67 & 68 & 90 & 80 & 67 \\
44 & 69 & 65 & 77 & 39 \\
17 & 35 & 100 & 71 & 22
\end{tabular}

\section{Table 3. Separation of glutathione S-transferases}

Rat tissue preparations and measurements of enzyme activity are described in the text. Non-enzymic reaction was less than $2 \%$ in all cases. All assays were at $\mathrm{pH} 6.5$ and $25^{\circ}$ for $5 \mathrm{~min}$. The numbers in parentheses are the numbers of separate experiments from which these results were averaged. Activities have been calculated as $\mu$ moles of thiol lost/min./g. of tissue.

Ratio of activity of undialysed rat liver supernatant to that of ammonium sulphate-fractionated acetic acid-precipitated rat liver homogenate (7)

Ratio of activity of dialysed rat liver supernatant to that of dialysed rat kidney supernatant (5)
Activity ratio towards

$\begin{array}{ccccc}\text { alkyl } & \text { aralkyl } & \text { aryl } & \text { alkene } & \text { epoxide } \\ 11.2 & 2.3 & 0.99 & 2.7 & 4.7 \\ 8.3 & 5 \cdot 1 & 47 \cdot 6 & 2.6 & 4 \cdot 1\end{array}$

liver supernatants prepared at different $\boldsymbol{g}$ values because dialysis or the lowering of the pH to $5 \cdot 0$ of a rat liver $70000 \mathrm{~g}$ supernatant gave similar results to those in Table 2. When glutathione $S$-transferases are compared, it is essential that all the substrates should be assayed with the same treated supernatant.

Adsorption of dialysed rat liver supernatant on calcium phosphate gel did not separate the activities of the enzymes, which were decreased by approx. $70 \%$.

Glutathione $S$-aryltransferase and $S$-alkene(cisester)transferase were more stable during acetone drying than the other enzymes (Table 2).

Fractionation of rat liver homogenates with $47 \%$ (w/v) ammonium sulphate followed by precipitation with acetic acid separated the activities of glutathione $S$-alkyltransferase, $S$-aralkyltransferase and $S$-aryltransferase (Table 3), suggesting that these enzymes are different, in agreement with results from heat-inactivation experiments (Fig. 1). However, glutathione $S$-aralkyltransferase was not clearly distinguished from $\boldsymbol{S}$-epoxidetransferase or $S$-alkene(cis-ester)transferase (Table 3).
Activities of dialysed rat liver and rat kidney supernatants. The ratio of activities in liver and kidney showed that glutathione $S$-aralkyltransferase is probably different from the other enzymes except for glutathione $S$-epoxidetransferase (Table 3). The values for the activity ratios were different from those obtained when undialysed preparations were assayed (Johnson, 1966; Boyland \& Chasseaud, 1967; Suga et al. 1967). It is possible that these enzymes in kidney are less stable to dialysis.

Distribution of activities in dialysed liver supernatants obtained from several animal species. The distribution of activities of the enzymes in several animal species differs, suggesting that these enzymes may be separate (Table 4). Glutathione $S$-alkyltransferase activity was greatest in pigeon and lowest in dog, ferret and human. Johnson (1966) obtained a similar result from human liver. Glutathione $S$-aryltransferase activity was high in guinea pig, dog and mouse, in agreement with the results of Grover \& Sims (1964). Glutathione S-epoxide. transferase activity has previously been measured only in the rat and in the ferret (Boyland \& Williams, 1965) and in various species of wild birds (Wit \& 
Table 4. Distribution of glutathione S-transferases in dialysed liver supernatants from different animal species

Preparation of liver supernatants and measurements of enzyme activity are described in the text. All assays were at $\mathrm{pH} 6.5$ and $25^{\circ}$ for $5 \mathrm{~min}$. Mice were $\mathrm{C}$ minus strain and rats were Chester Beatty strain. Liver supernatants had been either freshly prepared or stored at $-30^{\circ}$ for approx. 2 years.

\begin{tabular}{|c|c|c|c|c|c|c|}
\hline \multirow[b]{2}{*}{ Species } & \multirow{2}{*}{$\begin{array}{l}\text { Nos. and sex of } \\
\text { animals tested }\end{array}$} & \multicolumn{5}{|c|}{ Activity ( $\mu$ moles of thiol lost/min./g. of tissue) } \\
\hline & & alkyl & aralkyl & aryl & alkene & epoxide \\
\hline \multirow[t]{2}{*}{ Guinea pig } & $2\left(\sigma^{*}\right)$ & $1 \cdot 3,1 \cdot 2$ & $7 \cdot 4,7 \cdot 3$ & $1 \cdot 3,1 \cdot 3$ & $5 \cdot 7,6 \cdot 9$ & $\mathbf{1} \cdot \mathbf{9}, \mathbf{2} \cdot \mathbf{3}$ \\
\hline & $1\left(\sigma^{*}\right)^{*}$ & $\mathbf{2 \cdot 0}$ & $\mathbf{7 \cdot 0}$ & $1 \cdot 1$ & $8 \cdot 4$ & $\mathbf{2 \cdot 5}$ \\
\hline Pigeon & $6\left(\sigma^{*}\right)^{*} \dagger$ & $10 \cdot 7$ & $\mathbf{3} \cdot \mathbf{3}$ & $0 \cdot 4$ & $2 \cdot 7$ & $1 \cdot 0$ \\
\hline Rat & $>\mathbf{3 0}$ (아)*‡ & $3 \cdot 0$ & $\mathbf{2 \cdot 3}$ & 0.5 & $7 \cdot 5$ & $2 \cdot 1$ \\
\hline \multirow[t]{2}{*}{ Dog } & $1\left(\sigma^{*}\right)$ & $0 \cdot 4$ & $1 \cdot 1$ & $1 \cdot 1$ & $3 \cdot 4$ & $0 \cdot 8$ \\
\hline & $1($ (O) * & $0 \cdot 6$ & $2 \cdot 1$ & $1 \cdot 6$ & $2 \cdot 5$ & $1 \cdot 0$ \\
\hline Mouse & $20\left(\sigma^{*}\right)^{*} \dagger$ & $3 \cdot 5$ & $1 \cdot 9$ & $1 \cdot 2$ & $12 \cdot 2$ & $3 \cdot 0$ \\
\hline Hamster & $5\left(\sigma^{*}\right)^{*} \dagger$ & $1 \cdot 7$ & 1.9 & $0 \cdot 2$ & $6 \cdot 8$ & $1 \cdot 7$ \\
\hline Rabbit & $1\left(\sigma^{\top}\right)^{*}$ & $1 \cdot 1$ & $1 \cdot 1$ & $0 \cdot 7$ & $1 \cdot 7$ & $0 \cdot 3$ \\
\hline \multicolumn{7}{|l|}{ Human } \\
\hline Foetus & $2\left(\delta^{*}\right) \dagger$ & $0 \cdot 7$ & 0.7 & 0 & 0.9 & 0.5 \\
\hline Adult (post-mortem specimen) & 1 (9) & 0.8 & 0.5 & 0.04 & $1 \cdot 0$ & 0.4 \\
\hline Ferret & $2(\widetilde{)})$ & $0 \cdot 3,0.4$ & $0.4,0.2$ & $0.4,0.6$ & $4 \cdot 2,3 \cdot 7$ & $0 \cdot 7,0 \cdot 9$ \\
\hline & $\begin{array}{l}\text { * Fresh } \\
\text { † Poole } \\
\text { † Some }\end{array}$ & $\begin{array}{l}\text { repared } \\
\text { ssues. } \\
\text { livers w }\end{array}$ & $\begin{array}{l}\text { rnatant. } \\
\text { ooled. }\end{array}$ & & & \\
\hline
\end{tabular}

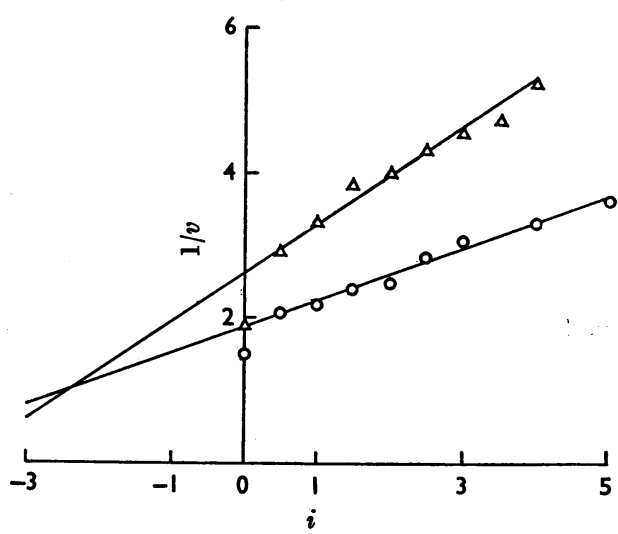

Fig. 2. Competitive-type Dixon (1953) plots for glutathione S-alkene(cis-ester)transferase obtained with GSH (O, $5 \mathrm{mM} ; \Delta, 2 \mathrm{mM}$ ) as substrate and GSSG as inhibitor. Incubation was for $6 \mathrm{~min}$. at $\mathrm{pH} \mathrm{6.5}$ and $25^{\circ}$ with diethyl maleate (5 $\mathrm{mm})$ and dialysed rat liver supernatant. $i$, Concn. of inhibitor (mM); $v$, initial velocity (GSH lost; mM).

Snel, 1968). The activities of this enzyme in man and rabbit were similar, and the amounts of the enzyme present in various animal livers varied over 10-fold compared with 40-fold for glutathione $S$ aryltransferase. Of the species examined, guinea pig was the best source of glutathione $S$-aralkyltransferase, and activities in ferret and human were

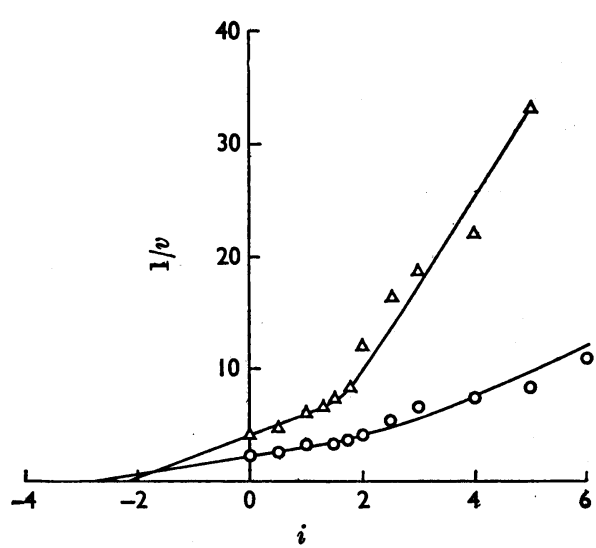

Fig. 3. Competitive-type Dixon (1953) plots for glutathione $S$-alkyltransferase obtained with GSH $(O, 3 \mathrm{mM} ; \triangle, 1.5 \mathrm{~mm})$ as substrate and GSSG as inhibitor. Incubation was for $6 \mathrm{~min}$. at $\mathrm{pH} 6.5$ and $25^{\circ}$ with methyl iodide $(3 \mathrm{~mm})$ and dialysed rat liver supernatant. $i$, Conen. of inhibitor (mM); $v$, initial velocity (GSH lost; $\mathrm{mM}$ ).

lowest. The activity of glutathione $S$-alkene(cis. ester)transferase in the livers was quantitatively of the same order as previous determinations (Boyland \& Chasseaud, 1967) when undialysed preparations were used. Although the distribution of glutathione $S$-epoxidetransferase and $S$-alkene(cis-ester)transferase was quantitatively of the same order, the 


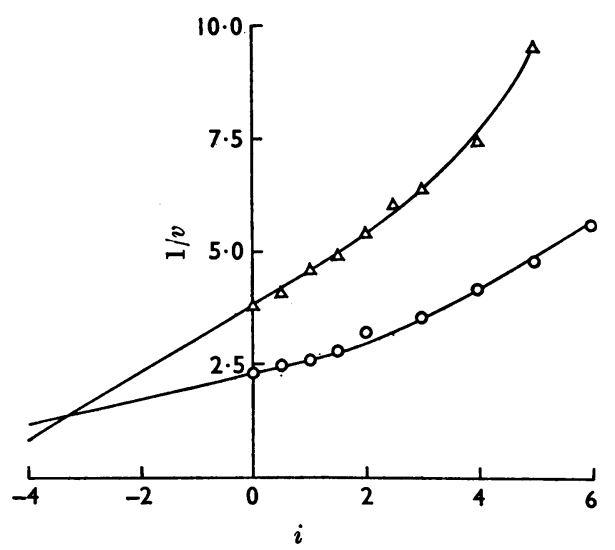

Fig. 4. Competitive-type Dixon (1953) plots for glutathione $S$-aralkyltransferase obtained with GSH (O, $3 \mathrm{mm;} \triangle$, $1.5 \mathrm{~mm}$ ) as substrate and GSSG as inhibitor. Incubation was for 6 min. at $\mathrm{pH} 6.5$ and $25^{\circ}$ with benzyl chloride ( $3 \mathrm{~mm}$ ) and dialysed rat liver supernatant. $i$, Concn. of inhibitor (mM); $v$, initial velocity (GSH lost; mM).

amounts of the latter varied over a slightly wider range of 13-fold (Table 4). The ratio was the reverse in the wild-bird liver preparations studied by Wit \& Snel (1968).

Inhibition of glutathione S-alkyltransferase, Saralkyltransferase and $\mathbf{S}$-alkene(cis-ester)transferase by GSSG. GSSG inhibits all known glutathione $S$. transferases that are present in rat liver supernatant preparations (E. Boyland, L. F. Chasseaud \& K. Williams, unpublished work).

The Dixon (1953) plot for glutathione $S$-alkene(cis-ester)transferase was linear and $K_{i}$ was $2 \cdot 3 \mathrm{~mm}$ (Fig. 2). However, the point on the graph representing zero inhibitor concentration fell below the ordinate at both fixed GSH concentrations, suggesting that the lines may curve downwards at lower inhibitor concentrations. Dixon (1953) plots were non-linear at high inhibitor concentrations for glutathione $S$-alkyltransferase (Fig. 3) and $S$-aralkyltransferase (Fig. 4), and the apparent inhibitor constants $\left(K_{i}^{\prime}\right)$ were $1.7 \mathrm{~mm}$ and $3.3 \mathrm{~mm}$. Johnson (1966) expressed the inhibition of glutathione $S$ alkyltransferase by GSSG with a LineweaverBurk plot that indicated that the inhibition was competitive.

Non-linearity of the Dixon (1953) plots (Figs. 3 and 4) may be due to the presence of two forms of the enzyme that differ in sensitivity to GSSG, inhibition of the more sensitive form being expressed by the linear part of the plot and inhibition of both forms being expressed by the non-linear part. Alternatively, two active sites on one enzyme may be present that are affected differently, e.g. a GSH. binding site and a second substrate-binding site. Also, oxidation of the enzyme may occur concurrently with competitive inhibition at higher GSSG concentrations. As evidence for the first possibility it was found that GSSG ( $5 \mathrm{~mm}$ ) did not inhibit these enzymes when present in a rat liver supernatant partially purified by ammonium sulphate fractiona. tion followed by acetic acid precipitation. This partially purified preparation may only contain a form of the enzyme that is less sensitive to GSSG, the form that is GSSG-sensitive having been removed or inactivated. Further, the composite nature of the heat-inactivation curves for glutathione S-transferases (Fig. 1, and Boyland \& Chasseaud, 1968a) indicate that two forms of each glutathione $S$. transferase may exist in rat liver supernatants.

The nature of the Dixon (1953) plots (Figs. 2, 3 and 4) for these glutathione $S$-transferases indicates that they are probably different enzymes.

Aralkyl esters. Aralkyl esters are metabolized to mercapturic acids in animals (Clapp, 1967 ; Hyde \& Young, 1968), and it is possible that the reaction of GSH with these esters may be catalysed by gluta. thione $S$-aralkyltransferase.

Of the esters assayed as substrates for conjugation with GSH catalysed by dialysed rat liver supernatant, benzyl formate, $p$-nitrobenzyl acetate, 1-menaphthyl acetate and 3,5-di-tert.-butyl-4hydroxybenzyl acetate reacted, but the enzymicreaction rate was very low. No reaction was observed between GSH and benzyl acetate or anthr-9-ylmethyl acetate.

Non-enzymic reaction with GSH was negligible for all compounds except 3,5-di-tert.-butyl-4hydroxybenzyl acetate, which reacted readily; more than $30 \%$ of the added material had reacted in $20 \mathrm{~min}$. at $\mathrm{pH} 6.5$ and $25^{\circ}$.

\section{DISCUSSION}

Identity of glutathione S-aralkyltransferase. Stekol (1938, 1940) isolated benzylmercapturic acid from the urine of animals after administration of benzyl chloride and its glutathione conjugate, $S$-benzylglutathione. Bray, James \& Thorpe (1958) showed that rabbits dosed with benzyl chloride excreted $49 \%$ of the dose as the mercapturic acid. Other aralkyl halides (Stekol, 1941; Bray et al. 1958; James \& White, 1967; Hyde \& Young, 1968) and aralkyl esters (Clapp, 1967; Hyde \& Young, 1968) are metabolized to mercapturic acids.

The reaction of benzyl chloride with GSH, an initial stage in mercapturic acid biosynthesis, is catalysed by glutathione $S$-aralkyltransferase, possibly an $S_{\mathrm{N}} 1$ type reaction (eqn.1); the concerted $\mathrm{S}_{\mathrm{N}} 2$ reaction seems less likely because GSH is a relatively large molecule. 


$$
\mathrm{Ph} \cdot \mathrm{CH}_{2} \mathrm{Cl} \longrightarrow\left[\begin{array}{l}
\left.\mathrm{Ph} \cdot \mathrm{CH}_{2}+\right] \stackrel{+\mathrm{GSH}}{\mathrm{Ph} \cdot \mathrm{CH}_{2} \cdot \mathrm{SG}}+\mathrm{H}^{+}+\mathrm{Cl}^{-} \\
\longrightarrow
\end{array}\right.
$$

Heat-inactivation experiments (Fig. 1), ammonium sulphate-fractionation and acetic acid-precipitation studies (Table 3), enzyme-inhibition studies with GSSG (Figs. 2, 3 and 4) and a consideration of the distribution of activities in rat liver and in rat kidney (Table 3) and in the livers of other animals (Table 4) showed that this enzyme was probably different from other known glutathione $S$-transferases.

Glutathione $S$-aralkyltransferase may be concerned with the reaction of GSH with aralkyl esters, and it may be involved in the metabolism of 3,5-ditert.-butyl-4-hydroxytoluene since this compound is excreted as a mercapturic acid after administration to rats (Daniel, Gage \& Jones, 1968). 3,5-Ditert.-butyl-4-hydroxybenzyl acetate reacts readily with GSH, probably through an intermediate carbonium ion (see eqn. 1), which may be the reactive intermediate formed from 3,5-di-tert.-butyl-4hydroxytoluene in vivo rather than the free benzyl radical suggested by Daniel et al. (1968).

Inhibition by GSSG. Although GSSG could inactivate glutathione $S$-transferases as a protein oxidant, it probably acts by competitively inhibiting these enzymes as a GSH conjugate (Figs. 2, 3 and 4). GSSG competitively inhibits glutathione $S$-aryltransferase and the $K_{i}$ was $0 \cdot 25 \mathrm{~mm}$ and the Dixon (1953) plot was linear (E. Boyland \& K. Williams, unpublished work). This result shows that glutathione $S$-aryltransferase differs from glutathione $S$-alkene(cis-ester)transferase (Fig. 2), $S$-alkyltransferase (Fig. 3) and $S$-aralkyltransferase (Fig. 4).

Species differences in mercapturic acid formation. Guinea-pig liver is a good source of several glutathione $S$-transferases (Table 4), yet this species forms little mercapturic acid in vivo from certain compounds, probably because of an inability to $N$-acetylate $S$-substituted cysteines (Bray, Franklin \& James, 1959). The extent to which mercapturic acid biosynthesis takes place in the human is largely unknown. However, the results in Table 4 and those of Grover \& Sims (1964), Johnson (1966) and Boyland \& Chasseaud (1967, 1968a) show that glutathione $S$-transferases are present in human liver and that GSH conjugation with foreign compounds can probably occur in the human in vivo.

Glutathione S-transferases. Reactions catalysed by known glutathione $S$-transferases are of two types: first, addition of GSH catalysed by glutathione $S$-alkenetransferases and $S$-epoxidetransferase; secondly, replacement by GSH catalysed by the remaining enzymes (Table 1). Apart from foreign compounds that are similar to substrates described in the present paper, glutathione $S$ transferases catalyse the reactions of GSH with $\beta$-propiolactone (Johnson, 1966), some organophosphorus compounds (Fukami \& Shishido, 1966; Hutson, Pickering \& Donninger, 1968; Morello, Vardanis \& Spencer, 1968), activated aryl nitro compounds (Al-Kassab et al. 1963), some nitrofurans (Williams, 1968), sulphobromophthalein (Combes \& Stakelum, 1961) and some alicyclic epoxides (Boyland \& Williams 1965). The properties and identity of these glutathione $S$. transferases are largely unknown, but some may be identical with the enzymes described in Table 1.

Boyland \& Chasseaud (1968b) have indicated that different enzymes catalyse reactions of GSH with $\alpha \beta$-unsaturated nitriles, sulphones and nitro compounds. Studies of glutathione $S$-aryltransferase and of the enzyme-catalysed reaction of GSH with 4-nitropyridine $N$-oxide and other nitro compounds in animal livers (E. Boyland \& K. Williams, unpublished work) and in wild-bird livers (Wit, 1968) have indicated that the enzymes concerned may be different. The existence of so many glutathione $S$ transferases may be necessary if GSH and the foreign compound are bound to the enzyme (Boyland \& Chasseaud, 1968a), otherwise, if only GSH were bound, one enzyme would be sufficient to activate it for reaction with any suitable electrophile. Glutathione $S$-transferases may act by increasing the ionization of bound-GSH, since non-enzymic reaction of GSH with many known or potential mercapturic acid precursors increases with increasing $\mathrm{pH}$ and subsequent ionization of GSH (e.g. reaction of GSH with diethyl maleate).

Several other foreign compounds are metabolized to mercapturic acids and are presumably conjugated with GSH before excretion, but the reaction may be non-enzymic or the nature of the enzymic reaction is unknown (see, e.g., Boyland \& Chasseaud, 1969). Two compounds that are metabolized to mercapturic acids, and whose spontaneous reaction with GSH is apparently unaffected by rat liver supernatant at neutral $\mathrm{pH}$ (E. Boyland \& L. F. Chasseaud, unpublished work), include benzothiazole-2-sulphonamide (Colucci \& Buyske, 1965 ) and arecoline (Boyland \& Nery, 1969).

Methyl iodide and benzyl chloride have been shown to be carcinogenic (Preussmann, 1968). Boyland \& Chasseaud (1968a) considered that a function of glutathione $S$-transferases was to protect cellular nucleophiles by conjugating such alkylating and aralkylating agents with GSH.

We thank Dr P. Sims for preparing the aralkyl esters and Dr K. Williams for helpful discussion. L.F.C. is grateful to the Medical Research Council for a grant. This investigation was supported by grants to the Chester Beatty Research Institute, Institute of Cancer Research: Royal Cancer Hospital from the Medical Research Council and the British Empire Cancer Campaign for Research. 


\section{REFERENCES}

Al-Kassab, S., Boyland, E. \& Williams, K. (1963). Biochem. J. 87, 4.

Barnes, M. M., James, S. P. \& Wood, P. B. (1959). Biochem. J. 71, 680.

Booth, J., Boyland, E. \& Sims, P. (1961). Biochem. J. 79, 516.

Boyland, E. \& Chasseaud, L. F. (1967). Biochem.J. 104, 95.

Boyland, E. \& Chasseaud, L. F. (1968a). Biochem. J. 109, 651.

Boyland, E. \& Chasseaud, L. F. (1968b). Rep. Brit. Emp. Cancer Campgn, 46, 27.

Boyland, E. \& Chasseaud, L. F. (1969a). Advanc. Enzymol. 32, 173.

Boyland, E. \& Nery, R. (1969). Biochem.J.113, 123.

Boyland, E. \& Williams, K. (1965). Biochem. J. 94, 190.

Bray, H. G., Franklin, T. J. \& James, S. P. (1959). Biochem. J. 73, 465.

Bray, H. G., James, S. P. \& Thorpe, W. V. (1958). Biochem. J. 70, 570.

Chasseaud, L. F. (1967). Ph.D. Thesis: University of London.

Clapp, J. J. (1967). Ph.D. Thesis: University of London.

Colucci, D. F. \& Buyske, D. A. (1965). Biochem. Pharmacol. 14, 457.

Combes, B. \& Stakelum, G. S. (1961). J. clin. Invest. 40, 981.
Daniel, J. W., Gage, J. C. \& Jones, D. I. (1968). Biochem.J. 106, 783.

Dixon, M. (1953). Biochem. J. 55, 170.

Fukami, J. \& Shishido, T. (1966). J. econ. Ent. 59, 1338.

Grover, P. L. \& Sims, P. (1964). Biochem. J. 90, 603.

Hutson, D. H., Pickering, B. A. \& Donninger, C. (1968). Biochem.J. 106, 20P.

Hyde, C. W. \& Young, L. (1968). Biochem.J. 107, 519.

James, S. P. \& White, D. A. (1967). Biochem. J. 104, 914.

Johnson, M. K. (1966). Biochem. J. 98, 44.

Morello, A., Vardanis, A. \& Spencer, E. Y. (1968). Canad.J. Biochem. 46, 885.

Parke, D. V. (1968). The Biochemistry of Foreign Compounds, p. 95. London: Pergamon Press Ltd.

Potter, V. R. \& Elvehjem, C. A. (1936). J. biol. Chem. 114, 4951.

Preussmann, R. (1968). Fd Cosmet. Toxicol. 6, 576.

Stekol, J. A. (1938). J. biol. Chem. 124, 129.

Stekol, J. A. (1940). Proc. Soc. exp. Biol., N.Y., 43, 108.

Stekol, J. A. (1941). J. biol. Chem. 138, 225.

Suga, T., Ohata, I., Kumaoka, H. \& Akagi, M. (1967). Chem. Pharm. Bull., Tokyo, 15, 1059.

Williams, K. (1968). Rep. Brit.Emp.CancerCampgn, 46, 28.

Wit, J. G. (1968). Europ. J. Pharmacol. 5, 100.

Wit, J. G. \& Snel, J. (1968). Europ. J. Pharmacol. 3, 370.

Woodward, G. E. \& Fry, E. G. (1932). J. biol. Chem. 97, 465. 